\title{
CONF-971207-- \\ BORON-ENHANCED-DIFFUSION OF BORON: THE LIMITING FACTOR FOR ULTRA-SHALLOW JUNCTIONS
}

\author{
Aditya Agarwal1,2, D. J. Eaglesham1, H.-J. Gossmann1, L. Pelaz1, S. B. Herner1, D. C. Jacobson1, \\ T. E. Haynes 2 , Y. Erokhin ${ }^{3}$, and R. Simonton ${ }^{3}$
}

1Bell Laboratories, Lucent Technologies, Murray Hill NJ 07974

2Solid State Division, Oak Ridge National Laboratory, Oak Ridge, TN 37831

${ }^{3}$ Semiconductor Equipment Operations, Eaton Corporation, Beverly MA 01915

Rem

OCT 279997

\begin{abstract}
Reducing implant energy is an effective way to eliminate transient enhanced diffusion (TED) due to excess interstitials from the implant. It is shown that TED from a fixed Si dose implanted at energies from 0.5 to $20 \mathrm{keV}$ into boron dopingsuperlattices decreases linearly with decreasing Si ion range, virtually disappearing at sub-keV energies. However, for sub$\mathrm{keV} \mathrm{B}$ implants diffusion remains enhanced and $x_{j}$ is limited to $\geq 100 \mathrm{~nm}$ at $1050^{\circ} \mathrm{C}$. We term this enhancement, which arises in the presence of $B$ atomic concentrations at the surface of $\approx 6 \%$, Boron-Enhanced-Diffusion (BED).
\end{abstract}

\section{Introduction}

It is currently projected that $0.07 \mu \mathrm{m}$ technology will require junction depths, $x_{j}, \approx 30 \mathrm{~nm}$. This places severe restrictions on the amount of transient enhanced diffusion (TED) which can be tolerated. If dopants are to be introduced by implantation, TED is inevitable due to the excess interstitials from the implant. However, it is hoped that TED can be reduced by reducing the implantation energy, thus placing the dopant and the implantation-induced excess interstitials closer to the surface which is a sink for interstitials. Consequently, ultra-low energy implantation is being widely pursued for shallow junctions for future device technologies (1), and a new generation of ultra-low energy commercial implanters is being designed. In this work, we show that reducing implant energy is an effective way to eliminate TED due to interstitials from the implant. However, for sub-keV B implants diffusion remains enhanced and $x_{j}$ is limited to $\geq 100$ $\mathrm{nm}$ at $1050^{\circ} \mathrm{C}$. This enhancement is also observed from evaporated $B$ layers arising in the presence of $B$ atomic concentrations at the surface of $\approx 6 \%$.

\section{TED from low-energy $\mathrm{Si}^{+}$implants}

We have quantified the reduction in TED with reduced implant energy using implantation of $\mathrm{Si}$ into boron-doping superlattices (B-DSL) containing B marker layers grown by molecular beam epitaxy (MBE) (2). Diffusion of the B marker layers (e.g. Fig.1) is profiled using SIMS and the diffusivity enhancement (ratio of observed diffusivity to

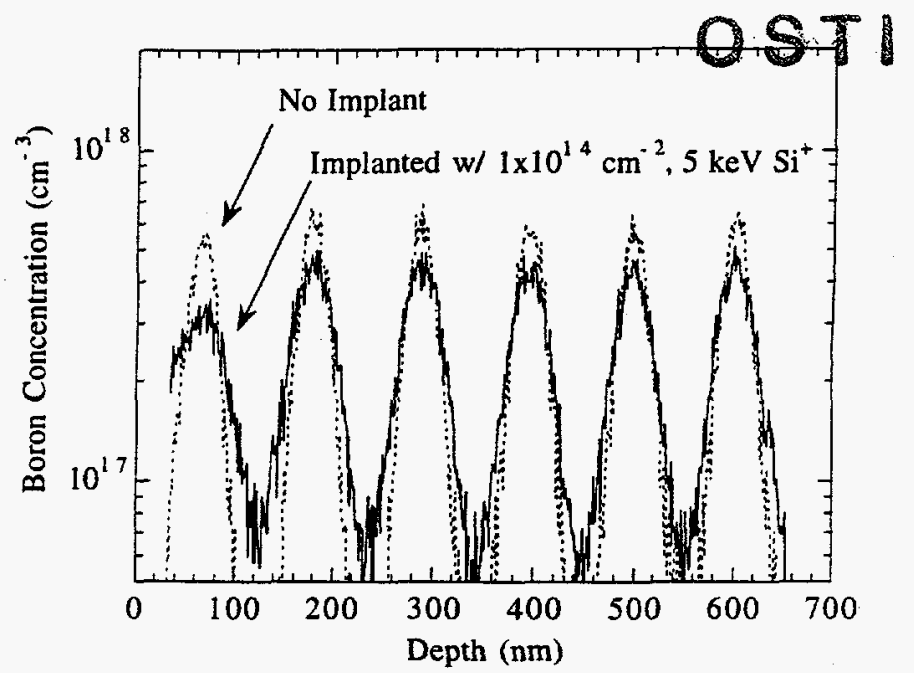

Fig.1 SIMS profiles comparing diffusion of $\mathrm{B}$ spikes during $600 \mathrm{~s}$ at $810^{\circ} \mathrm{C}$ in unimplanted and $5 \mathrm{keV} \mathrm{Si}+$ implanted $\mathrm{B}-$ DSL's. The $\mathrm{Si}^{+}$dose was $1 \times 10^{14} \mathrm{~cm}^{-2}$.

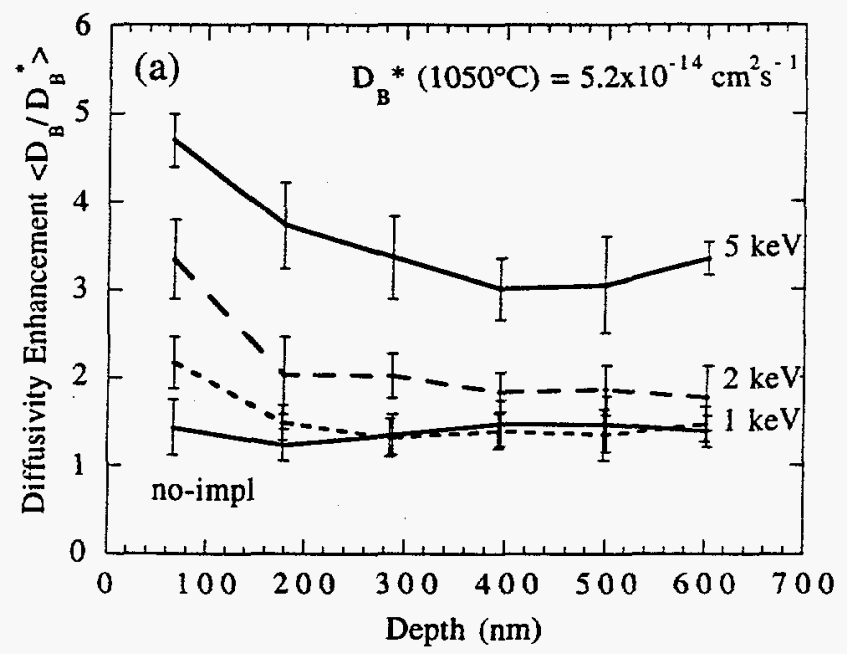

Fig.2(a) Diffusivity enhancement of B markers from a $1 \times 10^{14} \mathrm{~cm}^{-2} \mathrm{Si}^{+}$implant at $1-, 2-$, and $5-\mathrm{keV}$, following $1050^{\circ} \mathrm{C}, 10 \mathrm{~s}$ annealing, as a function of marker layer depth.

equilibrium diffusivity) is extracted for each marker layer using the process simulator PROPHET (3), which takes into account the standard concentration-dependence of $B$ diffusion. 


\section{DISCLAIMER}

This report was prepared as an account of work sponsored by an agency of the United States Government. Neither the United States Government nor any agency thereof, nor any of their employees, makes any warranty, express or implied, or assumes any legal liability or responsibility for the accuracy, completeness, or usefulness of any information, apparatus, product, or process disclosed, or represents that its use would not infringe privately owned rights. Reference herein to any specific commercial product, process, or service by trade name, trademark, manufacturer, or otherwise does not necessarily constitute or imply its endorsement, recommendation, or favoring by the United States Government or any agency thereof. The views and opinions of authors expressed herein do not necessarily state or reflect those of the United States Government or any agency thereof. 


\section{DISCLAmizR}

Portions of this document may be illegible in electronic image produets. Images are produced from the best available original document. 


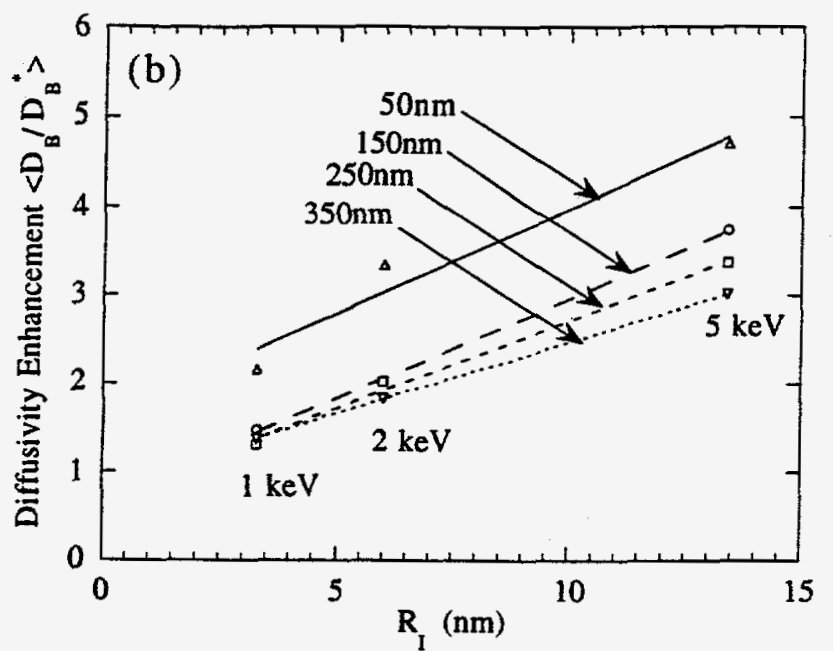

Fig.2(b) Boron diffusivity enhancement data from Fig.2(a), at $1050^{\circ} \mathrm{C}$ as a function of $R_{I}$, implant range (depth of excess interstitials).

The diffusivity enhancements from 1-, 2-, and 5-keV Si+ implanted and unimplanted B-DSL's are compared in Fig.2(a) as a function of marker layer depth. The enhancement decreases linearly with implant depth (i.e., the distance of the interstitials from the surface), as shown in Fig.2(b). The enhancement decreases from $-5 \times$ for $5 \mathrm{keV}$ implantation energy to $-2 \times$ for $1 \mathrm{keV}$, and extrapolates to $-1 \times$ for zero $\mathrm{keV}$. This is consistent with our expectation that at zero implantation energy (deposition), there would be no excess interstitials from the self-ion implantation and hence no TED. The same energy-dependent trend is observed at a lower temperature of $950^{\circ} \mathrm{C}$, and over nearly two orders of magnitude of energy (Fig.3). The reduction in TED with reduced self-ion implantation energy is due to increased interstitial annihilation at the surface which behaves as a perfect sink for interstitials (4). These Si-implant results demonstrate that in the range of annealing temperatures of interest for $p-n$ junction formation TED is virtually eliminated at sub-keV implantation energies.

\section{Ultra-shallow n-type junctions}

Results from these types of experiments can be directly extended for design of ultra-shallow $\mathrm{n}^{+}$junctions (5). By implanting $A s$ and $P$ at energies as low as 2 and $1 \mathrm{keV}$, respectively, TED can be minimized. Fig.4(a) and (b) show diffused dopant profiles for $2 \mathrm{keV} \mathrm{As}+$ and $1 \mathrm{keV} \mathrm{P}+$. with junction depths of 200 and $550 \AA$, respectively. Relatively high solid solubilities of As and P result in sheet resistance values of 600 and $450 \Omega / s q$, respectively. In each case, the sheet resistance can be reduced further by increasing the implantation dose.

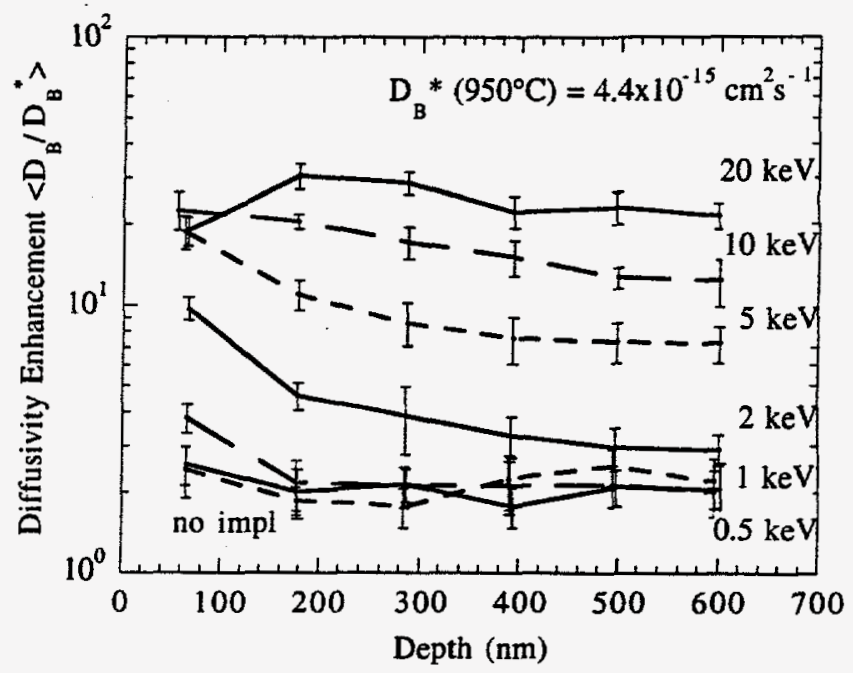

Fig.3 Diffusivity enhancement of B markers from a $1 \times 10^{14}$ $\mathrm{cm}^{-2} \mathrm{Si}^{+}$at $0.5-, 1-, 2-, 5-, 10-$, or $20-\mathrm{keV}$, following $950^{\circ} \mathrm{C}, 10 \mathrm{~s}$ annealing, as a function of marker layer depth.
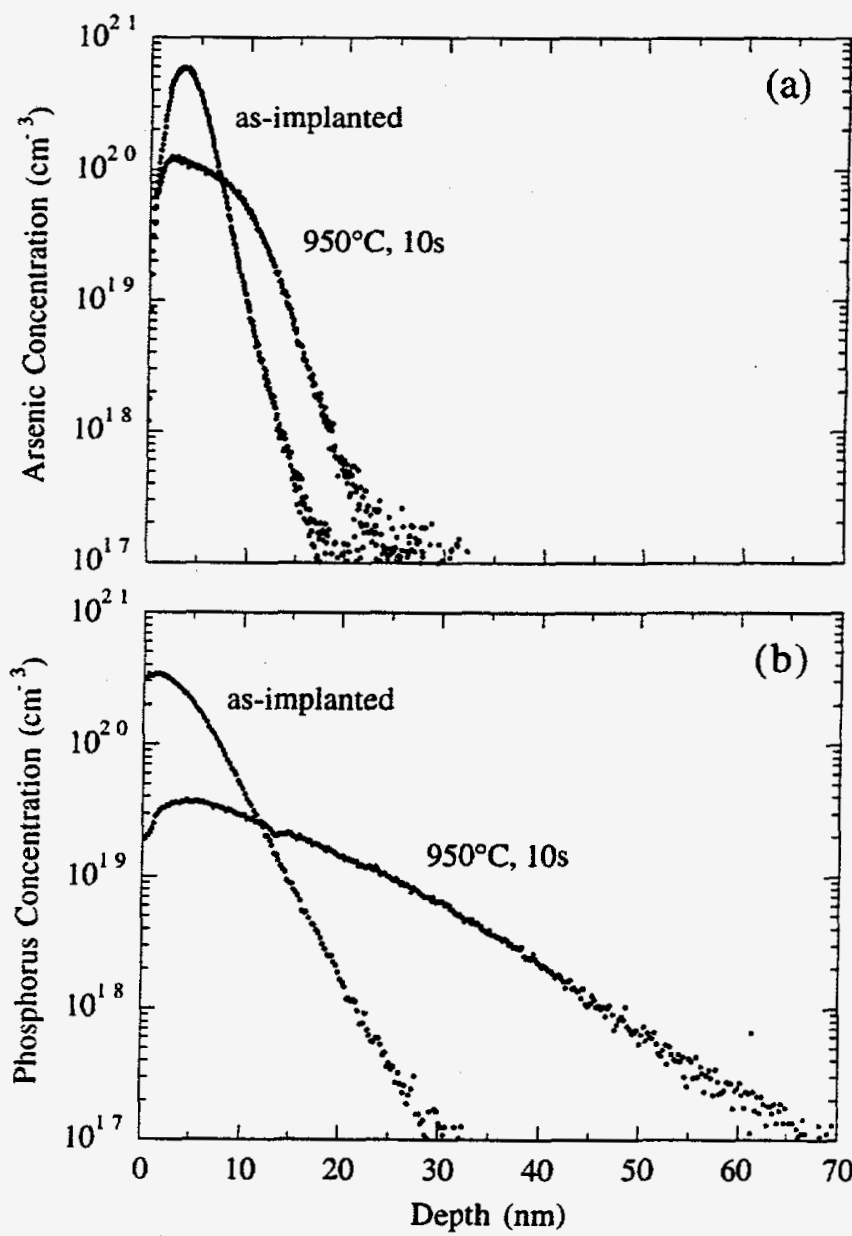

Fig.4 SIMS data comparing as-implanted and annealed depth profiles from (a) $3 \times 10^{14} \mathrm{~cm}^{-2}, 2 \mathrm{keV} \mathrm{As}+$, and (b) $3 \times 10^{14}$ $\mathrm{cm}^{-2}, 1 \mathrm{keV} \mathrm{P}^{+}$. Annealing conditions were $950^{\circ} \mathrm{C}$ for $10 \mathrm{~s}$. 

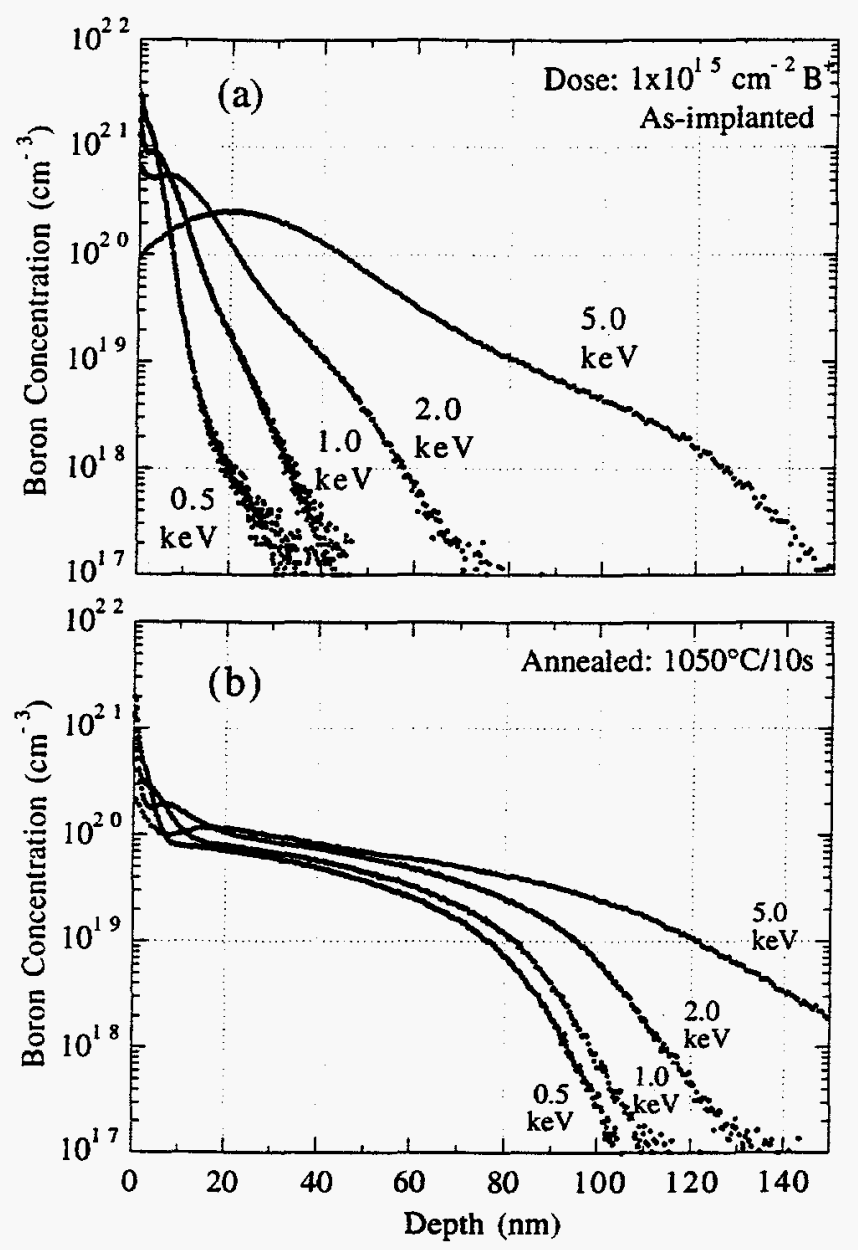

Fig.5 SIMS depth profiles of $1 \times 10^{15} \mathrm{~cm}^{-2}$ B implanted at $0.5-, 1-, 2-$, and 5-keV (a) as implanted, and (b) after annealing at $1050^{\circ} \mathrm{C}$ for $10 \mathrm{~s}$.

\section{Not-so-ultra-shallow p-type junctions}

In the case of $B$ implantation, however, we observe a saturation in the decrease in TED, and hence in $x_{j}$, with reduction in implantation energy. Figs.5(a) and (b) show depth profiles of $1 \times 10^{15} \mathrm{~cm}^{-2} \mathrm{~B}^{+}$implanted at $0.5-, 1-, 2-$, and $5-\mathrm{keV}$, before and after annealing at $1050^{\circ} \mathrm{C}$ for $10 \mathrm{~s}$. The diffusivity enhancements for the data in Fig.5(b) are plotted in Fig. 6 as a function of the boron ion projected range. The reduction in enhancement saturates at $-4 x$ when the implantation energy is reduced to 1 and $0.5 \mathrm{keV}$. Since the $\mathrm{Si}$ implantation results (Figs.2 and 3) demonstrate that TED can be effectively reduced by reducing implantation energy, this observation suggests that in the case of boron implantation there is some additional effect which leads to enhanced diffusivity. We call this effect Boron-Enhanced-Diffusion (BED). The BED effect is larger than that which can be accounted for by variation due to temperature control. Since TED is driven by excess interstitials there are two possible explanations for these findings; either the implantationinduced excess interstitials are not being annihilated at the

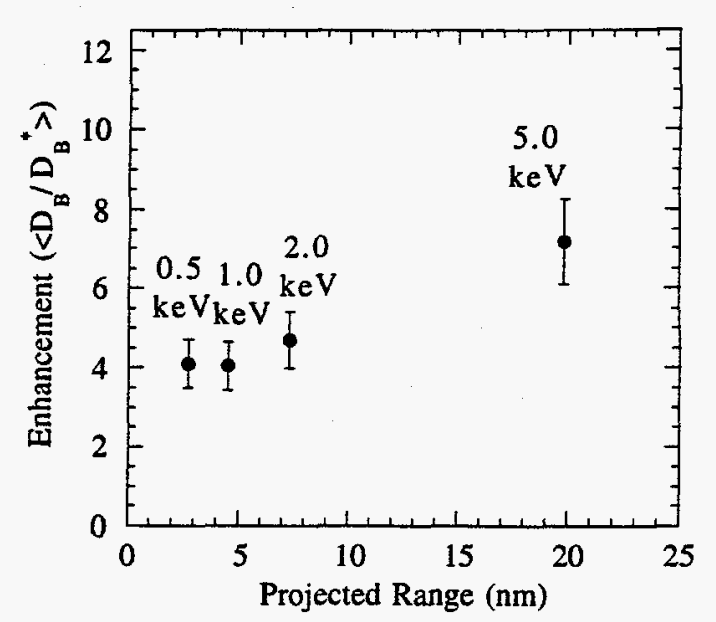

Fig.6 Diffusivity enhancements extracted from data in Fig.5(b) as a function of the B projected range.

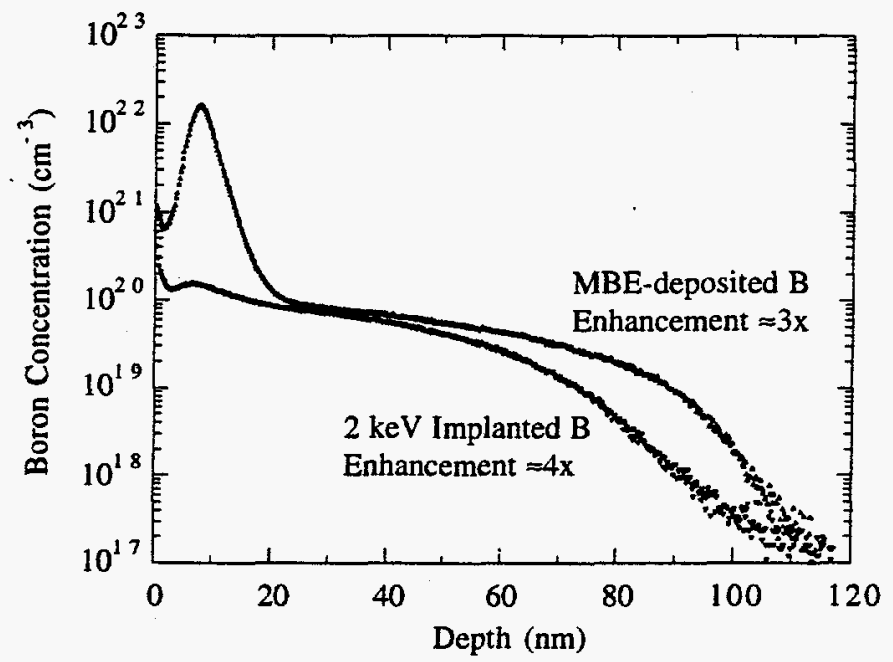

Fig.7 SIMS depth profiles comparing enhanced diffusion from MBE-deposited $\mathrm{B}$ and $1 \times 10^{15} \mathrm{~cm}^{-2} \mathrm{~B}+$ implant at 2 $\mathrm{keV}$, after annealing at $1050^{\circ} \mathrm{C}$ for $10 \mathrm{~s}$.

surface for shallow B implants (in contrast to the results from Si implants), or a greater number of excess interstitials are being generated from the shallower implanted B layer than from the deeper implants.

\section{Deposited boron}

To test the effect of surface $B$, we have measured the diffusivity enhancement from a B layer deposited onto Si by MBE. This represents the ultimate limit of ultra-low energy implantation since the $B$ atoms arrive at the surface at $\approx 0.0001 \mathrm{keV}$. Fig. 7 compares diffusion from the evaporated $B$ layer with that from a $2 \mathrm{keV} \mathrm{B}+$ implant. Diffusivity from the MBE-deposited $B$ layer is enhanced by a factor of $-3 \times$. Since there are no excess interstitials in the case of MBEdeposited boron and yet enhanced diffusion is observed, it seems likely that interstitials injected from the B layer are responsible for the observed BED. 

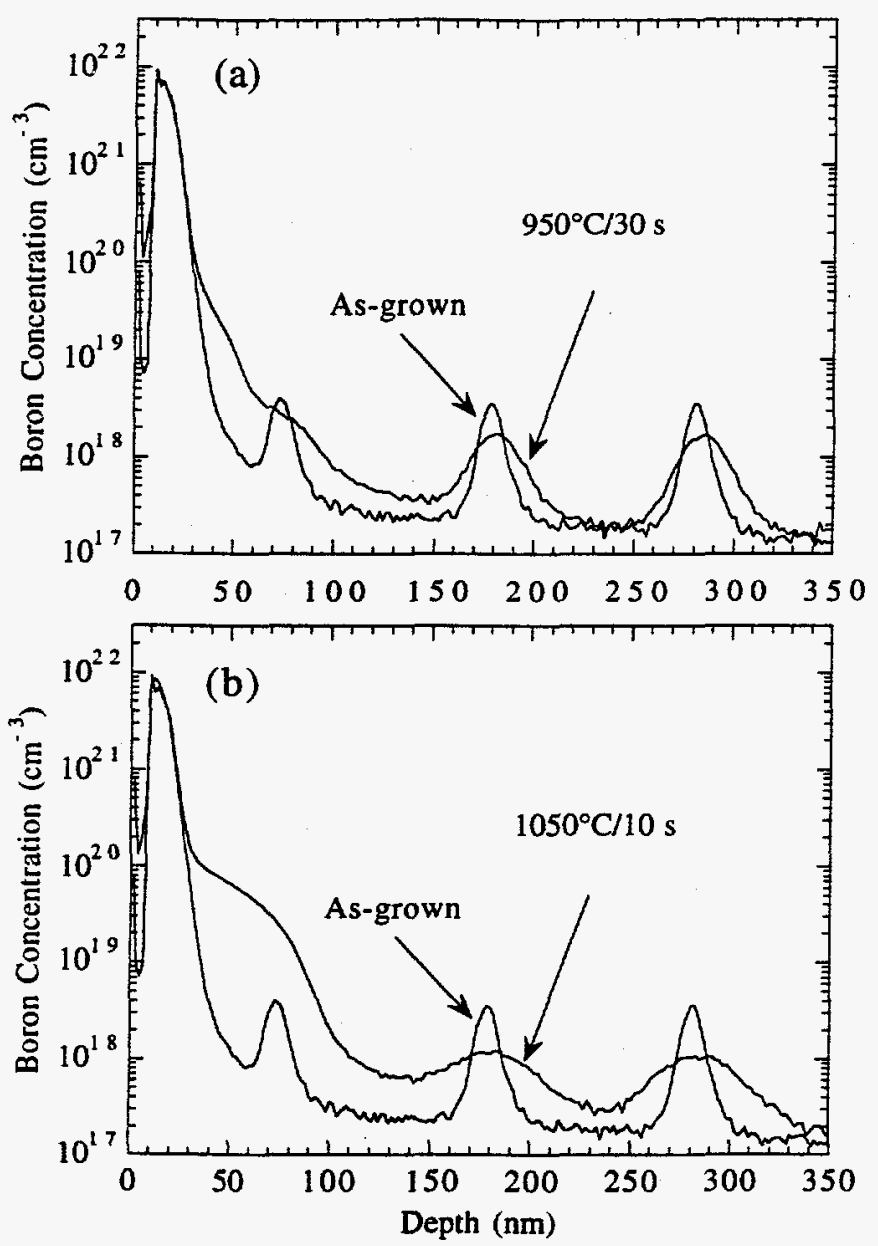

Fig.8 SIMS depth profiles comparing as grown and annealed MBE-grown B-DSL's containing an elemental B layer, annealed at (a) $950^{\circ} \mathrm{C}, 30 \mathrm{~s}$, and (b) $1050^{\circ} \mathrm{C}, 10 \mathrm{~s}$.

\section{SiB 4 phase transformation and interstitial injection}

Electron diffraction analysis of samples with MBE-deposited $B$ or high dose implanted layers reveals the presence of an amorphous layer even after annealing. Based on comparison with published $\mathrm{X}$-ray diffraction data we have indexed the diffraction pattern as $\mathrm{SiB}_{4}(6)$. It thus appears that when the $B$ concentration in the implanted layer exceeds a certain threshold, a separate silicon boride phase can be formed. It is possible that formation of this phase injects interstitials into the bulk. We have used specially designed B-DSL's, consisting of three $B$ marker layers, buried beneath a layer of evaporated $B$, to check for interstitial injection from the silicon boride layer via enhanced marker layer diffusion. Figs.8(a) and (b) compare as grown and diffused $B$ profiles after annealing at $950^{\circ} \mathrm{C} / 30 \mathrm{~s}$ and $1050^{\circ} \mathrm{C} / 10 \mathrm{~s}$, respectively; diffusion of the buried markers is enhanced by factors of $1.5 \mathrm{x}$ and $3.2 \times$, respectively. These experiments indicate that interstitial injection is indeed occurring from the high concentration boron layers. We assume that the $<50 \AA$ thin $B$ layer is not giving rise to a significant temperature difference because the optical properties of the wafer at $1050^{\circ} \mathrm{C}$ are dominated by free carriers. Based on minimum doses for $\mathrm{SiB}_{4}$ phase formation from 2 and $10 \mathrm{keV} \mathrm{B}$ implants, we estimate the threshold atomic $B$ concentration to be between 6 and $10 \%$. BED becomes important for ultra-shallow implants because the concentration of $\mathrm{B}$ increases rapidly as the energy is reduced.

\section{Summary}

We have investigated ultra-shallow junction formation using very low energy ion implantation. Using 0.5 to $20 \mathrm{keV} \mathrm{Si}$ implants into boron doping-superlattices it has been shown that transient enhanced diffusion, driven by implantationinduced excess interstitials, decreases linearly with the implant depth and virtually disappears at sub-keV energies. However, for sub-keV B implants diffusion remains enhanced, limiting junction depths to $>100 \mathrm{~nm}$ following $1050^{\circ} \mathrm{C} / 10 \mathrm{~s}$ annealing. This enhancement, which we call BED (boron-enhanceddiffusion), is also observed in several experiments involving boron layers deposited by molecular beam epitaxy where there is no implantation damage. BED correlates with the presence of high atomic concentration boron and is an additional effect to the standard concentration-dependence of boron diffusivity. Electron diffraction analysis has revealed formation of a silicon boride phase ( $\mathrm{SiB}_{4}$ ) when the boron concentration exceeds $6 \%$ and there is evidence that silicon boride phase formation leads to interstitial injection.

\section{References}

(1) see e.g. Proc. of the 4th Int. Workshop on Meas., Charact. \& Modeling of Ultra-shallow Doping Profiles, Research Triangle Park, 1997.

(2) H.-J. Gossmann, F. C. Unterwald, and H. S. Luftman, "Doping of Si thin films by low temperature molecular beam epitaxy," J. Appl. Phys. 73, 8237 (1993).

(3) M. R. Pinto, D. M. Boulin, C. S. Rafferty, R. K. Smith, et al, "Three dimensional characterization of bipolar transistors in a sub-micron BiCMOS technology using integrated process and device simulation," in IEDM 92, 1992, p. 923.

(4) Aditya Agarwal, H.-J. Gossmann, D. J. Eaglesham, L. Pelaz, D. C. Jacobson, T. E. Haynes, and Yu. E. Erokhin, "Reduction of transient enhanced diffusion from 1-5 $\mathrm{keV} \mathrm{Si}{ }^{+}$ion implantation due to surface annihilation of interstitials," Appl. Phys. Lett., in press.

(5) G. Timp, A. Agarwal, F. H. Bauman, M. Buonanno, T. Boone, V. Donnelly, et al, "Low Leakage ultra-thin gate oxides for extremely high performance sub-100nm nMOSFETs," this meeting.

(6) Aditya Agarwal, H.-J. Gossmann, D. J. Eaglesham, D. C. Jacobson, T. E. Haynes, J. Jackson, Yu. E. Erokhin, and John M. Poate, " 0.5 to $5 \mathrm{keV}$ ion implantation for ultra-shallow junctions," in Proc. of the 4th Int. Workshop on Meas., Charact. \& Modeling of Ultra-shallow Doping Profiles, Research Triangle Park, 1997, p. 39.1. 